ARAGÃO, F.A.S.; RIBEIRO, C.S.C.; CASALI, V.W.D.; GIORDANO, L.B. Cultivo de embriões de tomate in vitro visando a introgressão de genes de Lycopersicon peruvianum em L. esculentum. Horticultura Brasileira, Brasília, v. 20, n. 4, p. 605-610, dezembro 2002.

\title{
Cultivo de embriões de tomate in vitro visando a introgressão de genes de Lycopersicon peruvianum em L. esculentum
}

Fernando A. S. Aragão ${ }^{1}$; Cláudia S. da C. Ribeiro ${ }^{2}$; Vicente Wagner D. Casali ${ }^{3}$, Leonardo de B. Giordano ${ }^{2}$ Embrapa Hortaliças, C. Postal 218, 70.359-970 Brasília-DF;. ${ }^{3} U F V-D F T, 36.570-000$ Viçosa-MG, E-mail: aragao@enph.embrapa.br

\section{RESUMO}

Estudou-se diferentes protocolos de germinação e manutenção de híbridos interespecíficos (Lycopersicon esculentum X L. peruvianum) pela melhoria das condições de cultura in vitro bem como da aclimatação das plantas germinadas. Quanto à regeneração dos embriões, três formulações de meios de cultura para resgate de embrião foram avaliadas, em combinação com distintos períodos de tempo. A recuperação de híbridos interespecíficos foi influenciada pelo meio de cultura utilizado para o plaqueamento das sementes e pelo intervalo entre a polinização artificial e o plaqueamento. O meio HLH proporcionou os melhores resultados. O intervalo entre 25 e 35 dias após a polinização foi determinado como sendo o período ideal para recuperação. Para aclimatização, foram avaliadas plantas de $L$. esculentum, L. peruvianum, híbridos interespecíficos $\left(\mathrm{F}_{1}\right)$ e das gerações $\mathrm{RC}_{1}$ e $\mathrm{RC}_{2}$. $\mathrm{O}$ processo de aclimatização foi influenciado pelo tamanho das gemas utilizadas na repicagem anterior à aclimatização, pelos materiais genéticos utilizados e pelo tempo de manutencão das plântulas em tubo de ensaio. A geracão $\mathrm{F}_{1}$ apresentou a melhor capacidade de aclimatização. O período ideal para aclimatização variou entre 26 e 35 dias após a repicagem em tubo de ensaio. As aclimatizações realizadas sob condições ambientais amenas, alcançaram êxito total quanto à sobrevivência das plântulas.

Palavras-chave: meio de cultura, híbridos interespecíficos, aclimatização.

\begin{abstract}
Tomato embryo culture for introgression of genes of Lycopersicon peruvianum in L. esculentum

Three culture media in combination with distinct accessions, crossing generations and periods of time after artificial pollination were evaluated in order to identify more efficient protocols to recover interspecific hybrids between Lycopersicon esculentum and $L$. peruvianum. Both type of media for seed plating and the interval time for fruit harvest after artificial pollination had significant influence on the recovery of interspecific hybrids. The HLH medium gave the best results. The interval between 25 and 35 days after the artificial pollination was found to be the ideal for recovering interspecific hybrids. For acclimation, the L. esculentum and $L$. peruvianum plants were evaluated as well as plants of the interspecific hybrids $\left(\mathrm{F}_{1}\right)$ and those from the $\mathrm{RC}_{1}$ and $\mathrm{RC}_{2}$ generations. This process was affected by the size of the buds used in the seedling transfer before acclimation as well as by the accesses and the time period over which the plantlet was in the test tube. The hybrids presented a better acclimation ability. The ideal period ranged between 26 and 35 days after transferring the seedling to the test tube. The acclimation accomplished under mild environmental conditions improved the plantlet survival.
\end{abstract}

Keywords: culture media, interespecific hybrids, acclimatization.

(Recebido para publicação em 26 de março de 2001 e aceito em 10 de outubro de 2002)

A maioria dos genes de resistência a patógenos atualmente empregados no melhoramento genético do tomateiro cultivado (Lycopersicon esculentum Mill.) tem sido transferida via cruzamentos com espécies silvestres (Doganlar et al., 1997). L. peruvianum é considerada uma das mais importantes fontes doadoras de genes/alelos de resistência a doenças bem como de outras características de interesse agronômico e nutricional (Hogenboom, 1972a; Stevens \& Rick, 1986). Apesar de $L$. peruvianum apresentar um número de cromossomos idêntico ao de $L$. esculentum (Rick \& Buttler, 1956), o cruzamento entre essas duas espécies é, na maioria das vezes, incompatível, devido à existência de um conjunto de barreiras pré e pós-zigóticas. Esses híbridos interespecíficos podem apresen- tar formação deficiente ou degeneração do endosperma. Sementes viáveis não são formadas devido ao abortamento do embrião (Barbano \& Topoleski, 1984; Poysa, 1990; Kalloo, 1991). O início da degeneração do embrião híbrido é, aparentemente, devido a um colapso de células endospérmicas próximas ao suspensor e com a conseqüente proliferação de massas de calos endoteliais (Segeren et al., 1993). Deficiência do endosperma e proliferação endotelial são comumente observadas em cruzamentos interespecíficos, provavelmente devido à incompleta singamia (Kapil \& Tawari, 1978). Barbano \& Topoleski (1984) atribuíram à proliferação endotelial a única causa da degeneração do endosperma nos cruzamentos entre L. peruvianum $x$ L. esculentum.
A incompatibilidade sexual entre $L$. peruvianum e L. esculentum é unilateral. O grão de pólen de L. esculentum é incapaz de germinar no estigma de $L$. peruvianum, enquanto que o pólen de L. peruvianum germina no estigma de L. esculentum, ocorrendo ainda mecanismos distintos que impedem esta hibridação (Hogenboom, 1972b). Em alguns cruzamentos interespecíficos, a incompatibilidade é devida ao fracasso da germinação do pólen no estigma ou a falta de desenvolvimento do tubo polínico dentro do filete (Nettancourt et al., 1974a,b). Mistura de pólen de várias plantas de L. peruvianum permitiu que sementes híbridas iniciassem a formação do zigoto, ocorrendo alta freqüência da fertilização. Nestes cruzamentos podem ser observados o crescimento do tubo polínico e a fecundação. 
No entanto, o embrião aborta nos estádios iniciais de desenvolvimento (Thomas \& Pratt, 1981; Hogenboom, 1972b; Rick \& Buttler, 1956) devido a um fenômeno denominado incongruidade (Hogenboom, 1975).

A superação das barreiras interespecíficas é um dos mais importantes avanços no melhoramento de plantas, permitindo uma considerável expansão do conjunto gênico do tomateiro cultivado. Produtos químicos tais como o imuno-supressor cuprenil (Kesicki, 1979); cruzamentos entre linhagens de L. esculentum, com menores níveis de incompatibilidade com acessos de L. peruvianum (Rick, 1983); tratamento hormonal (Poysa, 1990); cruzamentos-ponte e técnicas de cultivo in vitro têm sido ferramentas utilizadas na recuperação de híbridos resultantes dos cruzamentos entre espécies naturalmente incompatíveis dentro do gênero Lycopersicon.

Métodos visando superar barreiras de incompatibilidade, via cultura in vitro, envolvem cultura de embrião (Smith, 1944); cultura de calos de embriões (Thomas \& Pratt, 1981; Poysa, 1990); cultura de óvulo (Imanishi et al., 1985; Ribeiro \& Giordano, 2001). Dentre essas técnicas, a cultura de embriões vem sendo a mais intensamente utilizada (Silva et al., 1995; Silva et al., 1998; Siqueira et al., 1988; Neal \& Topoleski, 1983; Nagai, 1984; Thomas \& Pratt, 1981; Smith, 1944). No entanto, somente baixas porcentagens de híbridos interespecíficos têm sido obtidas. Silva et al. (1995), produziram híbridos entre L. esculentum e L. peruvianum, com taxa de recuperação de embriões em torno de $1 \%$. O sucesso do resgate de híbridos interespecíficos em tais cruzamentos foi aparentemente influenciado por fatores genéticos, com alguns genitores apresentando níveis diferenciais de compatibilidade. Se existe aborto de embrião num estádio de desenvolvimento muito precoce, as plantas híbridas podem ser resgatadas via formação de calos e subseqüente recuperação a partir de massas de células embriônicas. $\mathrm{Na}$ maioria dos cruzamentos, a incompatibilidade permanece entre plantas $\mathrm{F}_{1}$, fazendo ainda necessário o uso de cultura de embrião na recuperação de plantas $\mathrm{RC}_{1}$ (Angora et al., 1981).
Existem casos onde as barreiras pószigóticas não envolvem apenas a degeneração do endosperma. Há situações em que o embrião não se desenvolve normalmente, não ocorrendo, portanto, a transição do tipo de desenvolvimento heterotrófico para autotrófico, sendo a cultura de embrião ineficaz (Poysa, 1990). Geralmente, espécies silvestres de Lycopersicon são tipos polimórficos havendo grande variação morfológica entre e dentro de populações/acessos da mesma espécie, permitindo, em muitos casos, que se obtenha hibridação interespecífica com sucesso (Kalloo, 1991). Portanto, a variabilidade de diferentes cruzamentos interespecíficos com L. esculentum é também utilizada como ferramenta na recuperação de embriões de híbridos interespecíficos (Rick, 1983; Segeren et al., 1993).

Uma análise crítica de todo este conjunto de informações sugere que a combinação de diferentes aspectos/estratégias em um único protocolo poderia aumentar a eficiência na obtenção de híbridos interespecíficos entre $L$. esculentum e L. peruvianum. Portanto, esse trabalho teve como objetivo estudar diferentes protocolos de germinação e manutenção desses híbridos interespecíficos pela melhoria das condições de cultura in vitro bem como da aclimatização das plântulas germinadas.

\section{MATERIAL E MÉTODOS}

Todo o trabalho foi realizado no laboratório de melhoramento genético e nas casas-de-vegetação da Embrapa Hortaliças.

\section{Obtenção de plantas híbridas}

\section{a) Genótipos utilizados}

Devido à existência da incompatibilidade unilateral (incongruidade), foi utilizado L. esculentum como genitor feminino e L. peruvianum como genitor masculino. O germoplasma de $L$. esculentum utilizado nos cruzamentos foi 'Floradade', por apresentar um grau de melhoramento menos avançado, preservar certa rusticidade, ter em seu pool gênico resistência a algumas doenças e obter moderada cruzabilidade com $L$. peruvianum; 'Santa Clara', por ser uma das cultivares de mesa mais difundidas no país e 'IPA-05', por ser uma das cul- tivares de tomate para processamento industrial mais cultivadas no Brasil. Pelo ótimo nível de resistência apresentado a diferentes doenças (Santos, 1996) e pela facilidade encontrada nos cruzamentos com L. esculentum, utilizou-se o acesso 'CNPH 947-1' de $L$. peruvianum. Técnicas de cultivo in vitro foram empregadas para recuperar e manter os híbridos interespecíficos.

\section{b) Obtenção de sementes híbridas}

As plantas de L. esculentum foram polinizadas artificialmente com pólen de L. peruvianum, coletado de flores recém abertas. Todas as flores polinizadas artificialmente foram etiquetadas. Frutos provenientes do referido cruzamento foram colhidos de 25 a 45 dias após a polinização. Foram usados o meio de cultura para germinação (HLH) e condições de cultivo propostos por Neal \& Topoleski (1983) (Tabela 1). As sementes, após excisadas e tratadas, foram colocadas para germinar em placas de Petri, contendo o meio, em câmara de germinação com temperatura de $25^{\circ} \mathrm{C}$, na ausência de luz. Utilizou-se o plaqueamento de sementes pela dificuldade de retirar os embriões das sementes e pela baixíssima taxa de resgate, alcançada com o plaqueamento de embriões (Ribeiro \& Giordano, 2001).

c) Meios de cultura e idade do embrião

Neste primeiro experimento objetivou-se otimizar o meio de cultura para germinação e definir uma data mais adequada para o plaqueamento das sementes, após a polinização artificial. Foram utilizadas as composições minerais do meio de Neal \& Topoleski (1983), e modificações deste meio, feitas no teor de sacarose e das vitaminas. As datas para plaqueamento variaram de acordo com as recomendações da literatura consultada (de 25 a 45 dias). $\mathrm{O}$ experimento apresentou uma configuração fatorial de 15 tratamentos (3 meios de cultura e 5 períodos após a polinização) e 5 repetições. Cada repetição correspondia a uma placa de Petri com 20 sementes. As modificações no meio HLH utilizadas foram HLH com as vitaminas $75 \%$ menos concentradas (proposta por Dr. Scott; comunicação pessoal) e HLH com sacarose 33,33\% menos concentrada (proposição deste tra- 
balho). Plaqueou-se sementes obtidas aos $25 ; 30 ; 35 ; 40$ e 45 dias após a polinização. Avaliou-se o número de embriões germinados e de embriões convertidos em plântulas, 30 dias após plaqueamento. Os genótipos utilizados neste experimento foram resultantes do cruzamento 'Floradade' $x$ 'CNPH 947-1'.

\section{Aclimatização de plântulas}

\section{a) Manutenção in vitro}

Para manutenção in vitro dos genótipos, utilizou-se o meio de cultivo com metade das concentrações do meio proposto por Murashige \& Skoog (1962), conforme proposto por Silva et al. (1995) (Tabela 1). O meio de cultivo era vertido em tubos de ensaio, para os quais eram transferidas somente as plântulas perfeitamente germinadas, do ponto de vista morfológico. Após a transferência dos acessos para os tubos, os mesmos eram tampados com um capucho de algodão e mantidos em sala especial, com temperatura variando entre 22 e $25^{\circ} \mathrm{C}$ e fotoperíodo de 18 horas, até que a planta preenchesse todo o tubo, e deste modo, estando apta à repicagem. Com o intuito de aumentar o número de clones de cada híbrido resgatado, foram realizadas sucessivas repicagens aproximadamente 30 dias após a repicagem anterior. Os híbridos interespecíficos, juntamente com seus parentais, foram mantidos tanto in vitro como em casade-vegetação, durante todo o experimento.

\section{b) Aclimatização}

$\mathrm{Na}$ aclimatização das plântulas, os tubos contendo as plântulas foram destampados e transferidos para o laboratório, onde permaneciam por aproximadamente 2 a 3 horas sobre a bancada, com ventilação natural. Passado esse período, os tubos foram levados para casa-de-vegetação, sendo distribuídas três plântulas de um mesmo acesso por vaso. Estes vasos foram mantidos sob as bancadas por período de 24 a 48 horas e, finalmente, transferidos para a parte superior das bancadas. O processo foi conduzido principalmente ao final do período da tarde, quando as condições ambientais eram mais amenas, reduzindo o estresse das plantas.

Neste experimento, estudou-se o melhor período de aclimatização das plântulas após a última repicagem. Fo-

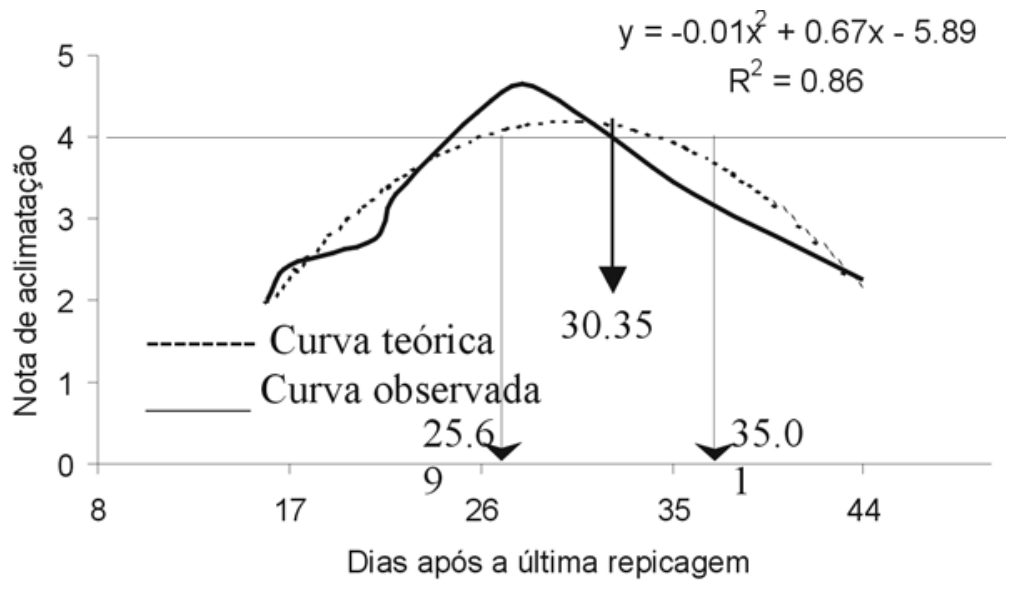

Figura 1. Aclimatização dos acessos de tomateiro cultivados in vitro com amplitude de 16 a 44 dias após a repicagem. Brasília, Embrapa Hortaliças, 2000.

ram aclimatizadas plântulas no intervalo de 16 a 73 dias após a repicagem, correspondendo a menor quantidade de dias que se conseguiu manusear as plântulas e o maior período que as plântulas resistiram em tubo, respectivamente. Quinze plântulas de cada genótipo avaliado, com o mesmo período de tempo em tubo, foram aclimatadas em vasos de 1,5 litro de solo autoclavado. Foram utilizados 5 vasos com três plântulas por genótipo. Notas subjetivas variando de 1 (péssimo) a 5 (ótimo), foram atribuídas individualmente às plantas, de acordo com seu aspecto visual. Estas avaliações foram realizadas 10 dias após a transferência das plântulas dos tubos para os vasos. Foi considerado ideal para aclimatização a planta obter, pelo menos, nota 4. Além dos híbridos, utilizouse seus genitores e gerações $\mathrm{RC}_{1}$ e $\mathrm{RC}_{2}$ obtidos por meio de retrocruzamentos com o genitor L. esculentum.

Os procedimentos biométricos de análise de variância e de regressão foram realizados pela utilização do aplicativo computacional "GENES" (Cruz, 2001 e Cruz \& Regazzi, 1994) da UFV. No procedimento de análise fatorial foi utilizado o aplicativo computacional "MSTATC" da Universidade de Michigan.

\section{RESULTADOS E DISCUSSÃO}

Pela análise fatorial (3 meios de cultura X 5 datas) o meio de cultura HLH original (Neal \& Topoleski, 1983) que apresentou a germinação de 16 embriões, obteve os melhores resultados. Contudo, não diferiu da formulação proposta neste trabalho que resultou na germinação de 10 híbridos interespecíficos. A modificação sugerida pelo Dr. Scott (comunicação pessoal), embora tenha regenerado menos híbridos, não diferiu da formulação proposta neste trabalho (Tabela 2). Apenas uma semente germinou nos três meios após 35 dias do plaqueamento, essa ocorreu na modificação proposta neste trabalho. Portanto, praticamente todos as germinações aconteceram de 25 a 35 dias após o plaqueamento, estando de acordo com os resultados de Duval (1992), Silva et al. (1998) e Ribeiro \& Giordano (2001). Embora, o maior número de germinações tenha ocorrido aos 30 dias, este período não difere de 25 e 35 dias após as polinizações. Observou-se neste trabalho que há necessidade de pesquisas adicionais para determinação do período ideal para recuperação de embriões de outras gerações $\left(\mathrm{RC}_{1}, \mathrm{RC}_{2}\right.$, etc.). É possível que estas sementes só estariam aptas à recuperação, em período mais tardio. A avaliação do período ideal de plaqueamento para recuperação dos genótipos de cada geração poderá elucidar estas observações.

Embora trinta e uma sementes tenham germinado nos três meios avaliados, apenas três converteram-se em plantas, duas aos 30 e uma aos 35 dias após o plaqueamento. Estas plantas foram obtidas no meio HLH. Para este 
Tabela 1. Composição nutricional dos meios 1⁄2 M.S. (cultivo in vitro) e HLH (germinação in vitro) para desenvolvimento de plântulas de tomate.

\begin{tabular}{|c|c|c|}
\hline Químicos & $1 / 2 M S(g / l)$ & HLH ( $g / l)$ \\
\hline$\overline{A I A}$ & 0,5 & --- \\
\hline Inositol & 0,1 & -- \\
\hline Sacarose & 20,0 & 60,0 \\
\hline \multicolumn{3}{|c|}{ Macronutrientes } \\
\hline $\mathrm{NH}_{4} \cdot \mathrm{NO}_{3}$ & 165,0 & 165,0 \\
\hline $\mathrm{KNO}_{3}$ & 95,0 & 95,0 \\
\hline $\mathrm{CaCl}_{2} \cdot 2 \mathrm{H}_{2} \mathrm{O}$ & 44,0 & 44,0 \\
\hline $\mathrm{MgSO}_{4} \cdot 7 \mathrm{H}_{2} \mathrm{O}$ & 37,0 & 37,0 \\
\hline $\mathrm{KH}_{2} \mathrm{PO}_{4} \cdot \mathrm{H}_{2} \mathrm{O}$ & 17,0 & -- \\
\hline $\mathrm{NaH}_{2} \mathrm{PO}_{4} \cdot \mathrm{H}_{2} \mathrm{O}$ & -- & 27,6 \\
\hline \multicolumn{3}{|c|}{ Micronutrientes } \\
\hline $\mathrm{H}_{3} \mathrm{BO}_{3}$ & 0,9280 & 0,6200 \\
\hline $\mathrm{MnSO}_{4} \cdot 4 \mathrm{H}_{2} \mathrm{O}$ & 1,6900 & 2,2300 \\
\hline $\mathrm{ZnSO}_{4} \cdot 4 \mathrm{H}_{2} 0$ & 1,1500 & 0,8600 \\
\hline $\mathrm{Kl}$ & 0,0830 & 0,0830 \\
\hline $\mathrm{Na}_{2} \mathrm{MoO}_{4} \cdot 4 \mathrm{H}_{2} \mathrm{O}$ & 0,0242 & 0,0250 \\
\hline $\mathrm{CuSO}_{4} \cdot 5 \mathrm{H}_{2} \mathrm{O}$ & 0,0375 & 0,0025 \\
\hline $\mathrm{CoCl}_{2} \cdot 6 \mathrm{H}_{2} \mathrm{O}$ & 0,0238 & 0,0025 \\
\hline \multicolumn{3}{|c|}{ Solução concentrada de Fe.EDTA } \\
\hline $\mathrm{Na}_{2}$.EDTA & 2,78 & 2,78 \\
\hline $\mathrm{FeSO}_{4} \cdot 7 \mathrm{H}_{2} \mathrm{O}$ & 3,73 & 3,73 \\
\hline \multicolumn{3}{|c|}{ Vitaminas } \\
\hline Tiamina & 0,10 & 0,10 \\
\hline Glicina & 0,05 & 0,20 \\
\hline Ácido Nicotínico & 0,05 & 0,05 \\
\hline Piridoxina & 0,05 & 0,05 \\
\hline $\mathrm{PH}$ & 5,8 & 5,8 \\
\hline Autoclavegem & $121^{\circ} \mathrm{C} / 15 \mathrm{~min}$ & $121^{\circ} \mathrm{C} / 15 \mathrm{~min}$ \\
\hline
\end{tabular}

1/2M.S.=Metade das concentrações do meio proposto por Murashige \& Skoog, 1962.

caso, não foi realizada análise estatística. Nas sementes germinadas e não revertidas em plântulas perfeitas ocorreu apenas a formação da parte epígea ou hipógea, ou ainda, formou-se somente um calo sem diferenciação alguma. Esta observação indica que outros ajustes na composição deste meio deverão ser avaliados com o intuito de melhorar a taxa de regeneração. Portanto, a recuperação dos híbridos com técnicas de cultura de embriões, além de ser influenciada pelos acessos utilizados nos cruzamentos interespecíficos (Rick, 1983; Kalloo, 1991), é bastante influenciada pelo meio de cultivo e pelo intervalo entre a polinização artificial e o plaqueamento das sementes. Duval (1992), especulou que o meio de cultura não é o principal fator no desenvolvimento e formação de plântulas. Entretanto, neste trabalho, não foi avaliada a importância relativa dos fatores.

Ao se abranger toda a amplitude alcançada (16 a 73 dias após a repicagem), a aclimatização dos acessos proporcionou uma curva associada a uma equação polinomial do quarto grau com o coeficiente de determinação de 0,90 . Como consideramos o ideal para aclimatização a planta atingir pelo menos média quatro, de acordo com essa curva de quarto grau, o período ideal para aclimatização seria de $25(24,77)$ a $30(29,99)$ dias após a repicagem. Entretanto, como a utilização de uma equa- ção do quarto grau para explicar eventos biológicos é questionável, adotamos uma curva estimada na amplitude de 16 a 44 dias após a última repicagem. $\mathrm{O}$ critério adotado para este intervalo foi o genótipo apresentar média de aclimatização 2 ou mais, além de que acima deste período, praticamente todo o meio já foi consumido. Assim, apesar de apresentar uma menor faixa no período ideal de aclimatização e um menor coeficiente de determinação $(0,86)$, é mais segura de ser explorada (Figura 1). Deste modo, o período ideal (com base em média 4) para aclimatização dos acessos foi estimado de $26(25,69)$ a 35 $(35,01)$ dias após a repicagem, coincidindo do ponto de vista prático, com o 
Tabela 2. Número de sementes híbridas (L. esculentum x L. peruvianum) germinadas. Brasília, Embrapa Hortaliças, 2000.

\begin{tabular}{lcccccc}
\hline \multirow{2}{*}{ Meio } & \multicolumn{7}{c}{ Dias após a polinização } & \multirow{2}{*}{ Média } \\
\cline { 2 - 6 } & $\mathbf{2 5}$ & $\mathbf{3 0}$ & $\mathbf{3 5}$ & $\mathbf{4 0}$ & $\mathbf{4 5}$ & \\
\hline HLH & 4 & 7 & 5 & 0 & 0 & $3,20 \mathrm{a}$ \\
Scott & 1 & 2 & 2 & 0 & 0 & $1,00 \mathrm{~b}$ \\
Proposto & 2 & 4 & 3 & 1 & 0 & $2,00 \mathrm{ab}$ \\
\hline Média & $2,33 \mathrm{ab}$ & $4,33 \mathrm{a}$ & $3,33 \mathrm{a}$ & $0,33 \mathrm{bc}$ & $0,00 \mathrm{c}$ & 2,07 \\
\hline
\end{tabular}

período adotado nas realizações das sucessivas repicagens. De acordo com esta curva quadrática, o máximo é atingido durante o trigésimo dia (30,35 dias).

A análise de variância dos valores de aclimatização dos genótipos indicou comportamento diferenciado entre às gerações. Pelo teste de Tukey verificouse a superioridade estatística da população $F_{1}$ (híbridos) em relação aos parentais (Figura 2). Por outro lado, os híbridos não diferiram das gerações subseqüentes $\left(\mathrm{RC}_{1}\right.$ e $\left.\mathrm{RC}_{2}\right)$, a $5 \%$ de significância. Essas diferenças constatadas devem estar associadas à heterose.

Provavelmente as plântulas seriam melhor adaptadas em um período de aclimatização mais tardio, porém em torno de 30 a 35 dias após a repicagem, as plântulas atingem o algodão no topo do tubo, iniciando um enrolamento da parte apical, dificultando o seu desenvolvimento, o que prejudica a aclimatização. Outro fator importante é a disponibilidade do meio de cultivo ser menor à medida que o tempo passa. Assim, o desenvolvimento das plântulas também foi limitado pelo tamanho dos tubos.

A impossibilidade de uniformização das gemas utilizadas nas repicagens também influencia no crescimento das plântulas e, conseqüentemente, no resultado final da aclimatização. Este resultado, ainda pode ser influenciado por distintas condições climáticas, o que pode ser eliminado pela aclimatização simultânea de acessos. No entanto, todas as plântulas submetidas ao processo de aclimatização adotado sobreviveram. Este resultado tem importância na manutenção de germoplasma que eventualmente poderia ser perdido na aclimatização.

A recuperação dos híbridos por meio de técnicas de cultura de embriões é bastante influenciada pelo meio de cultivo e pelo intervalo entre a polinização

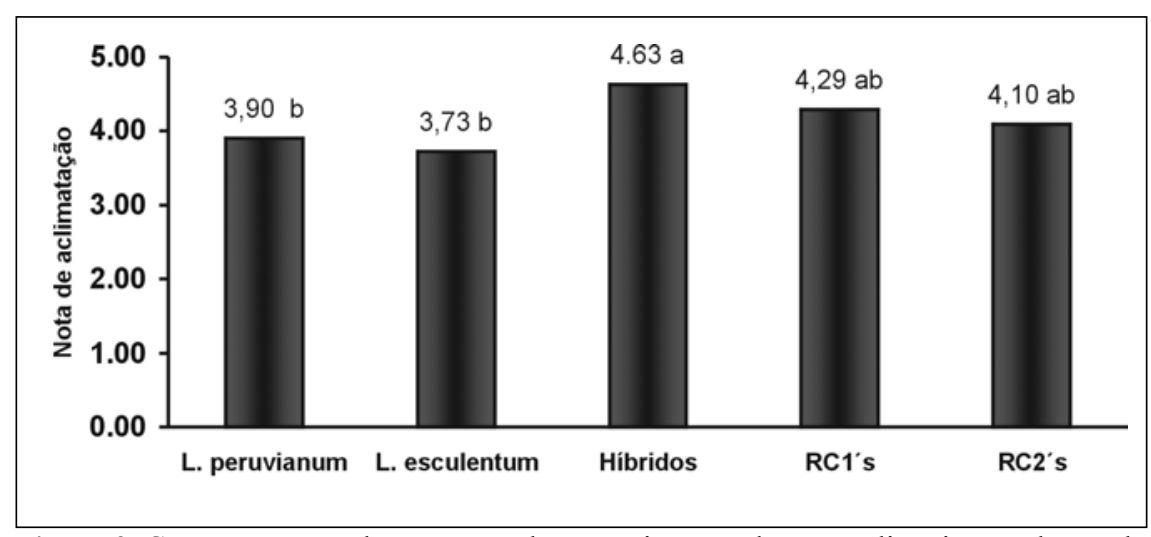

Figura 2. Comportamento das gerações de tomateiro em relação à aclimatização dentro do intervalo estimado como ótimo (de 25,69 a 35,01 dias após a repicagem). Brasília, Embrapa Hortaliças, 2000.

artificial e o plaqueamento das sementes. As modificações no meio para germinação HLH, avaliadas neste trabalho, não foram mais eficientes do que a formulação original, proposta por Neal \& Topoleski (1983). No período de 25 a 35 dias após a polinização, os embriões dos híbridos interespecíficos de tomate estão aptos à recuperação, estando em um bom estádio de desenvolvimento para germinação. Quanto ao período ideal para aclimatização dos genótipos, este varia entre 26 e 35 dias após a repicagem. Os híbridos $\left(\mathrm{F}_{1}\right)$ apresentaram heterose significativa em relação à aclimatização e, não diferiram das demais gerações $\left(\mathrm{RC}_{1}\right.$, e $\left.\mathrm{RC}_{2}\right)$. A aclimatização é influenciada pelo tamanho das gemas utilizadas na repicagem, pelo genótipo aclimatado e pelo tempo de permanência da plântula no tubo. O processo de aclimatização adotado neste trabalho foi considerado eficiente.

\section{AGRADECIMENTO}

Ao Sr. Antonio Francisco Costa, funcionário da Embrapa Hortaliças, que auxiliou de maneira relevante neste laborioso trabalho.

\section{LITERATURA CITADA}

ANGORA, G.; SACCARDO, F.C.M.E.; SREE, R.K. Backcross progenies from Lycopersicon esculentum L. x hybrid (L. esculentum x $L$. peruvianum Mill). Z. Pflanzenzucht, v. 87, p. 153157, 1981.

BARBANO, P.P.; TOPOLESKI, L.D. Postfertilization hybrid seed failure in Lycopersicon esculetum x Lycopersicon peruvianum ovule. Journal American Society Horticultural Science, v. 109, p. 95-100, 1984.

DOGANLAR, S.; FRARY, A.; TANSKESLEY, S.D. Production of interespecific $\mathrm{F}_{1}$ hybrids, $\mathrm{BC}_{1}$, $\mathrm{BC}_{2}$ and $\mathrm{BC}_{3}$ populations between Lycopersicon esculentum and two accessions of peruvianum carrying new root-knot nematode resistance genes. Euphityca, v. 95, p. 203-207,1997.

DUVAL, C.M. Metodologia de avaliação de germoplasma de Lycopersicon, visando resistência ao vírus de vira-cabeça do tomateiro e obtenção de híbridos entre L. esculentum X $L$. peruvianum, através de cultura de tecidos. Brasília, UnB, 1992. 119 p. (Tese mestrado)

HOGENBOOM, N.G. Breaking breeding barriers in Lycopersicon. 1. The genus Lycopersicon, its breeding barrier and the importance of breaking these barriers. Euphytica, v. 1, p. 221-227, 1972a. HOGENBOOM, N.G. Breaking breeding barriers in Lycopersicon. 2. in L. peruvianum (L.) Mill. Euphytica, v. 21, p. 228-243, 1972 b.

HOGENBOOM, N.G. Incompatiblity and incongruity $p$. two different mechanisms for the non-functioning intimate partner relationships. Proceedings R. Society London B. v. 188, p. 361375, 1975. 
IMANISHI, S.; WATANABE, Y.; HIURA, I. A simple and efficient method for the interespecific hybridization between Lycopersicon esculentum e L. peruvianum. Journal Yamagata Agricultural Society, v. 42, p. 13-15, 1985.

KALLOO, G. Interespecific and intergeneric hibridization in tomato. In: Genetic improvement of tomato. Berlin: Springer-Verlag, 1991.p.73 - 82. KAPIL, R.N. ;TAWARI, S.C. The integumentary tapetum. Botanic Review, v.44, p.457-490, 1978. KESICKI, E. New hybrid between $L$. esculetum and L. peruvianum. Tomato Genetic Coop. Rep., v.29, p.28, 1979.

MURASHIGE, T.; SKOOG, F. A revised medium for rapid growth and bioassays with tobacco tissue culture Physiologia Plantarum, v.15, p.437-497, 1962.

NAGAI, H. Criação de variedades de tomate resitentes a viroses. Fitopatologia Brasileira Brasília,v.9, n.2, p.307-308, 1984.

NEAL, C.A.; TOPOLESKI, L.D. Hormonal regulation of growth and development of tomato embryos in vitro. Journal of the American Society for Horticultural Science, v. 110, p. 869-873, 1983. NETTANCOURT, D.; DEVREUX, M.; LANERI, U.; CRESTI, M.;PACINI, E.; SARFATTI, G Genetical and ultrastructural aspects of the selfand cross incompatibility in interespecific hybrids between self-compatible mechanism in Lycopersicon esculentum self-incompatible $L$. peruvianum. Theoretical and Applied Genetics, v. 44 , p. 278-288, 1974a.
NETTANCOURT, D.; SACCARDO, F.; LANERI, U.; CAPPACCIO, E.; WESTEFORD, M.; ECOCHARD, R. Self-compatibility in a spontaneous tetraploid of Lycopersicon peruvianum Mill. Int. Atom. En., v. 44, p. 278288, 1974b.

POYSA, V. The development of bridge lines for interespecific gene transfer between Lycopersicon esculentum and L. peruvianum. Theoretical and Applied Genetics, v. 79, p. 187-192, 1990.

RIBEIRO, C.S.C.; GIORDANO, L.B. Método de obtenção de híbridos interespecíficos entre $L$. esculentum e L. peruvianum. Pesquisa Agropecuária Brasileira, Brasília, v. 36, n. 5, p. 793-799, 2001.

RICK, C.M.; BUTLER, L. Cytogenetics of the tomato. Advances in genetics, v. 8, p. 267-382, 1956.

RICK, C.M. Crossability between L. esculentum and a new race of L. peruvianum. Tomato Genet. Coop. Rep., v. 333, p. 13, 1983.

SANTOS, J.R.M. Methodology for screening tomato for Fusarium wilt, Verticilium wilt, Gray leaf spot, Early blight and Septoria leaf spot. In: INTERNATIONAL CONFERENCE ON THE PROCESSING TOMATO 1., INTERNATIONAL SYMPOSIUM ON TROPICAL tomato Diseases 1., 1996, Recife. Proccedings... Alexandria: ASHS / IPA, 1997.
SEGEREN, M.I.; SONDAHL, M.R.; SIQUEIRA, W.J.; MEDINA FILHO, H.P.; NAGAI, H.; LOURENÇÃO, A.L. Revista Brasileira de Genética, Ribeirão Preto, v. 16, n. 2, p. 367-380, 1993. SILVA, C.; GIORDANO, L.B.; SANTOS, J.R.M. Híbridos interespecíficos entre $L$. esculentum e $L$. peruvianum. Horticultura Brasileira, Brasília, v. 13, n. 1, p. 113, 1995. Resumo.

SILVA, C.; ARAGÃO, F.A.S.; GIORDANO, L.B. Introgressão de genes de resistência à Septoria lycopersici de Lycopersicon peruvianum em tomate. Horticultura Brasileira, Brasília, v. 16, n. 1, 1998. Resumo.

SIQUEIRA, W.J.; FONSECA, M.I.S.; SONDHAL, M. Regeneração de plantas híbridas entre L. esculentum e L. peruvianum a partir de calos com dois anos de cultura "in vitro". Bragantia, v. 47, n. 1, p. 1-8, 1988.

SMITH, P.G. Embryo culture of tomato species hybrid. American Society for Horticultural Science, v. 44, p. 413-416, 1944.

STEVENS, M.A.; RICK, C.M. Genetics and breeding. In p. ATHERTON, J.G.; RUDICH, J. The tomato crop: a scientific basis for improvement. Chapman \& Hall, London, 1986. p. 34-109.

THOMAS, B.R.; PRATT, D. Efficient hybridization between Lycopersicon esculentum and L. peruvianum via embryo callus. Theoretical and Applied Genetics, v. 59, p. 215-219, 1981. 